\title{
Characterization of the Friction Coefficient of Aluminum Alloy 6061 in Ultra-Precision Machining
}

\author{
Hailong Wang ${ }^{1} \mathbb{D}$, Tao Zhang ${ }^{2}$, Sujuan Wang ${ }^{1,2, *}$ and Suet To $^{3}$ \\ 1 State Key Laboratory of Precision Electronic Manufacturing Technology and Equipment, Guangdong \\ University of Technology, Guangzhou 510006,China; whl_nick@163.com \\ 2 Guangdong Provincial Key Laboratory of Micro-Nano Manufacturing Technology and Equipment, School of \\ Electromechanical Engineering, Guangdong University of Technology, Guangzhou 510006, China; \\ g158351789@gmail.com \\ 3 State Key Laboratory in Ultra-precision Machining Technology, The Hong Kong Polytechnic University, \\ Hong Kong, China; Sandy.To@polyu.edu.hk \\ * Correspondence: grace.wangsj@gdut.edu.cn; Tel.: +86-20-2388-0655
}

Received: 7 February 2020; Accepted: 2 March 2020; Published: 3 March 2020

\begin{abstract}
Aluminum alloy 6061(Al6061), an Al-Mg-Si alloy, is a precipitation-hardened alloy. The generation of precipitate affects its mechanical properties, and induces a worse surface finish during diamond cutting. The friction coefficients of the tool-chip and tool-workpiece interfaces influence temperature rise, and are therefore important predictors of tool wear and surface integrity during the diamond cutting of Al6061. This study investigated the relationship between precipitate generation and the friction coefficients of Al6061. Groups of experiments were conducted to study the influence of temperature and heating time on the number of precipitates and the friction coefficients. The results show that the generation of AlFeSi particles induces cracks, scratch marks and pits on diamond-machined Al6061 and affects the cutting forces. Moreover, the variation trend of the friction coefficient of Al6061 under different heating conditions agrees well with that of the number of AlFeSi particles. This implies that, during ultra-precision machining of precipitation-hardened alloys, cutting-induced heat causes precipitates to form on the chips and machined surface, changing their material properties. This affects the tool-workpiece and tool-chip contact conditions and the mechanisms of chip formation and surface generation in ultra-precision machining.
\end{abstract}

Keywords: friction coefficient; precipitates; aluminum alloy 6061(Al6061); ultra-precision machining

\section{Introduction}

Aluminum alloy 6061(A16061) is being used more and more widely, for instance in transportation, as a result of its light weight, moderate strength and good forming ability [1,2]. Al6061 (chemical composition by wt \%: $\mathrm{Mg} 0.92, \mathrm{Si} 0.76, \mathrm{Fe} 0.28, \mathrm{Cu} 0.22$, Ti0.10, Cr0.07, $\mathrm{Zn0} 0.06, \mathrm{Mn} 0.04$ and Al balance) is an age-hardenable 6000 series aluminum alloy. In this alloy, $\mathrm{Mg}$ and $\mathrm{Si}$ are the main alloying elements, and contribute to strengthening by precipitating intermetallic phases during heat treatment [3]. Although precipitation can help to enhance the mechanical properties of 6000 series alloys [4], it also has some detrimental effects, such as on their corrosion resistance [5], and on the surface finish obtained during the machining process (by causing scratch marks, pits and cracks [6]).

It is well known that the work done and the power consumed during the cutting process is largely converted into heat. This is dissipated through the cutting tool, the chips and the workpiece material. It has been reported that the temperature in ultra-precision machining ranges from $250{ }^{\circ} \mathrm{C}$ to $400{ }^{\circ} \mathrm{C}$ [7], and machining error due to thermal deformations of the cutting tool and the workpiece during ultra-precision diamond turning has been found to reach the order of a few micrometers [8]. Some 
studies have also shown that elevated temperatures can change flow stress in the workpiece material, and have a dominant influence on the rate of tool wear and on the generation of a thermo-deformation layer in the machined surface [9].

Therefore, more information concerning the effect of heat on the cutting process is essential for improving that process-especially in ultra-precision machining, which aims at sub-micrometer form accuracy and nanometer surface roughness. In our previous study, it was found that different cutting parameters (including spindle speed, cut depth and feed rate) induce different temperature rises on the machined surface, and therefore generate different sizes and numbers of precipitates during ultra-precision raster milling of Al6061 [10]. In fact, precipitate generation in Al6061 not only affects the surface finish during machining [6], but also its material properties. This was ignored in our previous studies $[6,10]$ but it is an important factor affecting material removal and chip formation in the ultra-precision machining process.

In the context of ultra-precision machining of Al6061, it is even more important, since the heat dissipated through the chips and workpiece materials also induces the generation of precipitated phases and changes their mechanical properties, affecting the mechanisms of chip formation and surface generation.

\section{Diamond Cutting Experiment}

A diamond cutting experiment was conducted on an ultra-precision machine system (Moore Nanotech 350 FG, Swanzey, NH, USA). Single straight cutting was performed on a flat surface, with depth of cut and cutting speed rate equal to $8 \mu \mathrm{m}$ and $500 \mathrm{~mm} / \mathrm{min}$, respectively. The feeding/cutting direction was parallel to the Y-axis in the machine coordinate system, as shown in Figure 1 . The workpiece material was Al6061 and the cutting tool was a single-crystal diamond tool, with a nose radius, front clearance angle and rake angle of $2.06 \mathrm{~mm}, 10^{\circ}$ and $0^{\circ}$, respectively. A high-speed camera was used to observe the cutting process, as shown in Figures 1 and 2. Figures 3 and 4 present the scanning electron microscope (SEM) images of the generated chip and the machined surface of the diamond-machined Al6061.
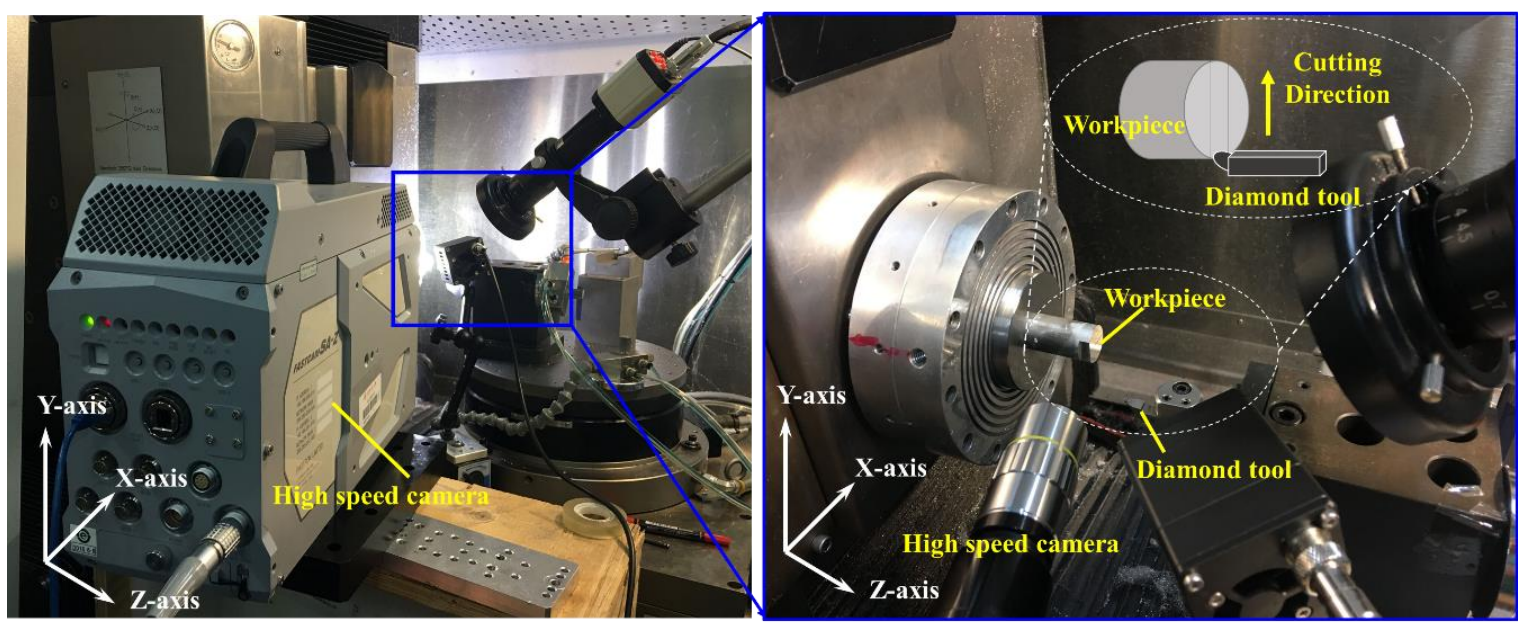

Figure 1. Observation of the diamond cutting process with a high-speed camera.

During material removal, there are three main deformation regions (the primary, the secondary and the tertiary deformation zones) and two interfaces (the tool-chip and tool-workpiece interfaces), as shown in Figure 3. Deformation in the primary deformation zone is due to the plastic at the shear plane. In the secondary deformation zone, the work done deforms the chip and overcomes the sliding friction at the tool-chip interface. In the tertiary deformation zone, the work done overcomes the friction at the rubbing contact between the tool clearance face and the newly machined surface. Hence, heat generated in the primary and secondary zones is highly dependent on the cutting parameters, tool 
geometry and material properties, while heat in the tertiary zone is mostly affected by the clearance angle $(\beta)$ of the cutting tool and the elastic recovery height $\left(h_{e r}\right)$ of the material [11].

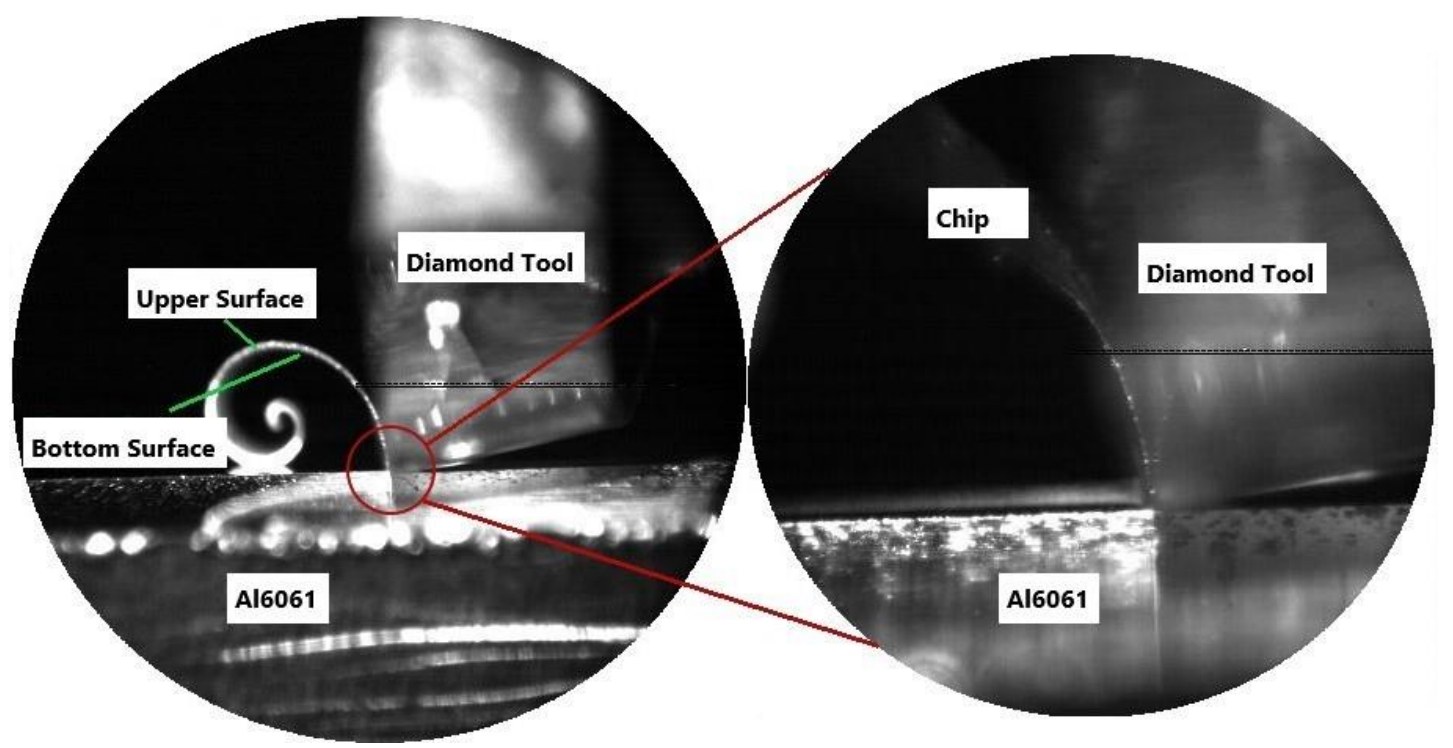

Figure 2. Observation of chip formation in orthogonal diamond cutting of Al6061.

Meanwhile, as shown in Figure 3 (illustrating the three deformation zones), there are two interfaces: the tool-chip interface and the tool-workpiece interface. It has been found that friction at the two interfaces has a huge influence on the temperature rise during the machining process [12], and is of strategic interest as a predictor of wear [13] and surface integrity [14]. In particular, the development of a numerical cutting model requires friction models of the two interfaces [15]. At the tool-chip interface, the bottom surface of the chip (Figure 2) is a newly formed surface with high strain hardening, and the hardness of the chip can be twice as high as that of the workpiece because of the plastic deformation in the chip [9]. This hardness variation changes the tool-chip friction coefficient, affecting heat generation in the secondary deformation zone.

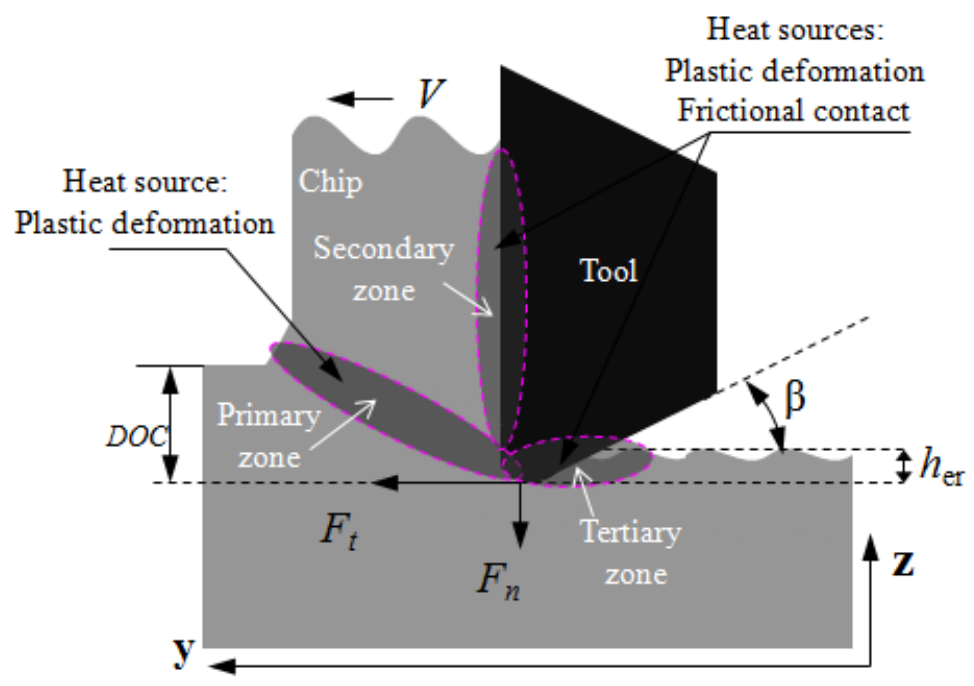

Figure 3. Three deformation zones and two interfaces in ultra-precision machining.

Scanning electron microscope (SEM) images of the formed chip are shown in Figure 4 . There are many black particles and a smaller number of white particles on the upper surface of the chip (Figure $4 a$ ), and the bottom surface of the chip has an especially serrated form (Figure $4 b$ ). Different 
types and amounts of precipitation imply that different temperatures were generated on the top and bottom surfaces of the chip during diamond cutting of A16061, while the serrated form indicates high plastic deformation on the chip. This also implies that the friction coefficient of the tool-chip interface was changed due to the generation of particles on the upper surface of the chip, since friction coefficient is related to many factors, such as the material's properties, surface topography and load [16].
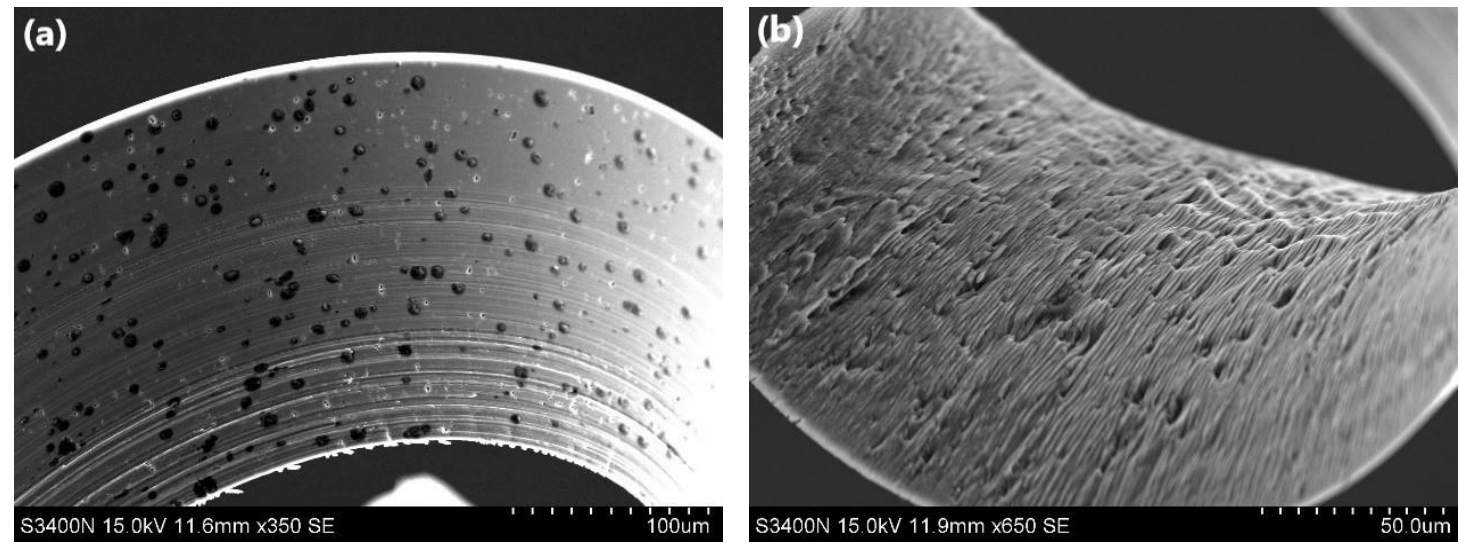

Figure 4. SEM images of different positions of the formed chip: (a) upper surface, (b) bottom surface.

Some studies have shown that the temperature rise on the workpiece is due to the work done in the primary and territory deformation zones [17,18]. Therefore, the heat generated on the machined surface mainly depends on the workpiece material and the thermo-physical properties of the cutting tool material [19], which are also crucial predictors of temperature distribution and heat dissipation at the tool-workpiece interface [20]. In ultra-precision machining, the decrease in the thermal mass of the chip makes the partitioning of thermal energies quite different to that of conventional machining [9]. Meanwhile, the natural diamond single crystals have a conductivity of $24-25 \mathrm{~W} / \mathrm{cm} / \mathrm{K}$ at $300 \mathrm{~K}$ [21], more than ten times that of cutting tools used in conventional machining (e.g., carbon steel workpieces and cemented carbide tools) [22].

Figure 5 is an SEM image of the surface generated during the diamond cutting of Al6061. Compared with the uncut surface (the surface above the green line in Figure 5), there are many white and black precipitates, cracks, pits and scratch marks on the diamond-machined surface. The cracks are due to the failure of adhesion between the particle phase and Al6061 base surface near the diamond cutting tool, while the pits are due to particles dropping out from the machined surface. The scratch marks are due to the rubbing of particles moving with the diamond tool in the cutting process. These include particles which drop from the base surface and parts of particles cut by the diamond tool.

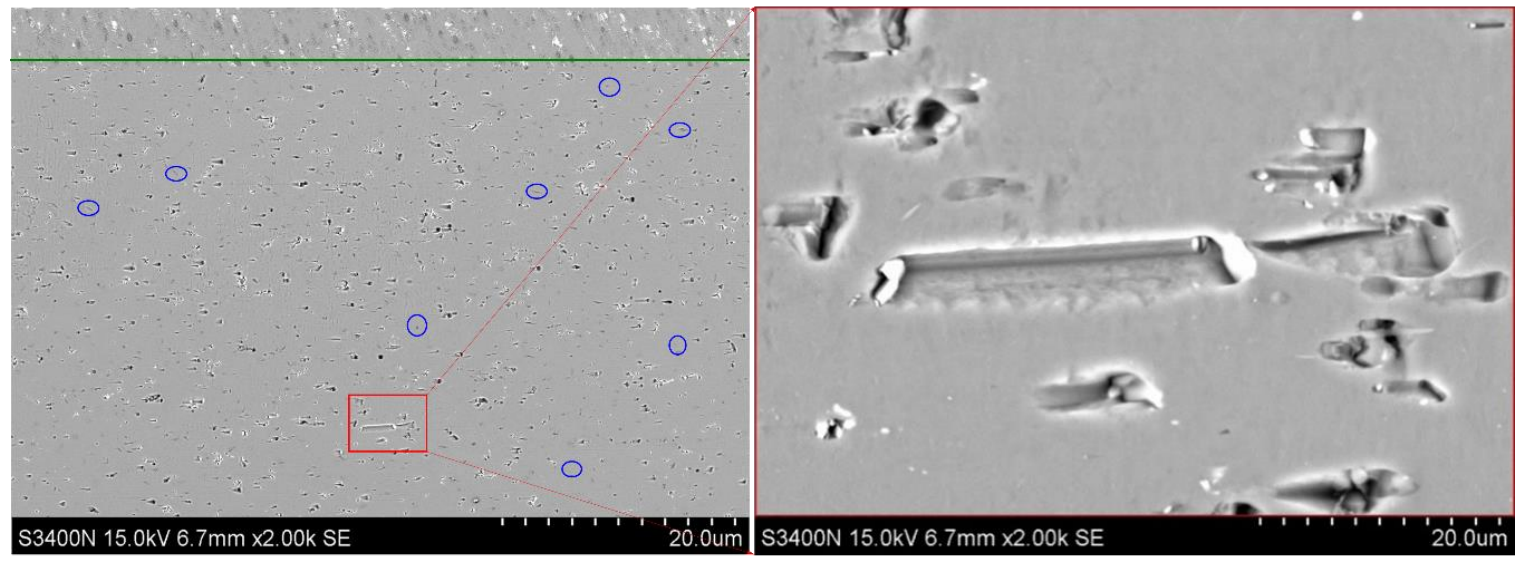

Figure 5. SEM images of the freshly generated surface of Al6061. 
Figure 6 shows the force measurements for diamond cutting of Al6061. It can be seen that the force signals in the $\mathrm{Y}_{-}$, and $\mathrm{Z}$-directions $\left(\mathrm{F}_{y}\right.$ and $\mathrm{F}_{z}$ in Figure 6) fluctuate when there are scratch marks on the machined surface (see the blue circles in Figure 6). This is partly because the hardness of the particles is greater than that of Al6061, resulting in relatively larger forces. Another reason is that the phase particles generated on the machined surface change the tool-workpiece interface friction properties, which changes the cutting forces in two directions ( $\mathrm{F}_{n}$ and $\mathrm{F}_{t}$ in Figure 3 ). This in turn affects heat generation on the tertiary deformation zone. Above all, the extent of the force change is related to the size and number of the particles.
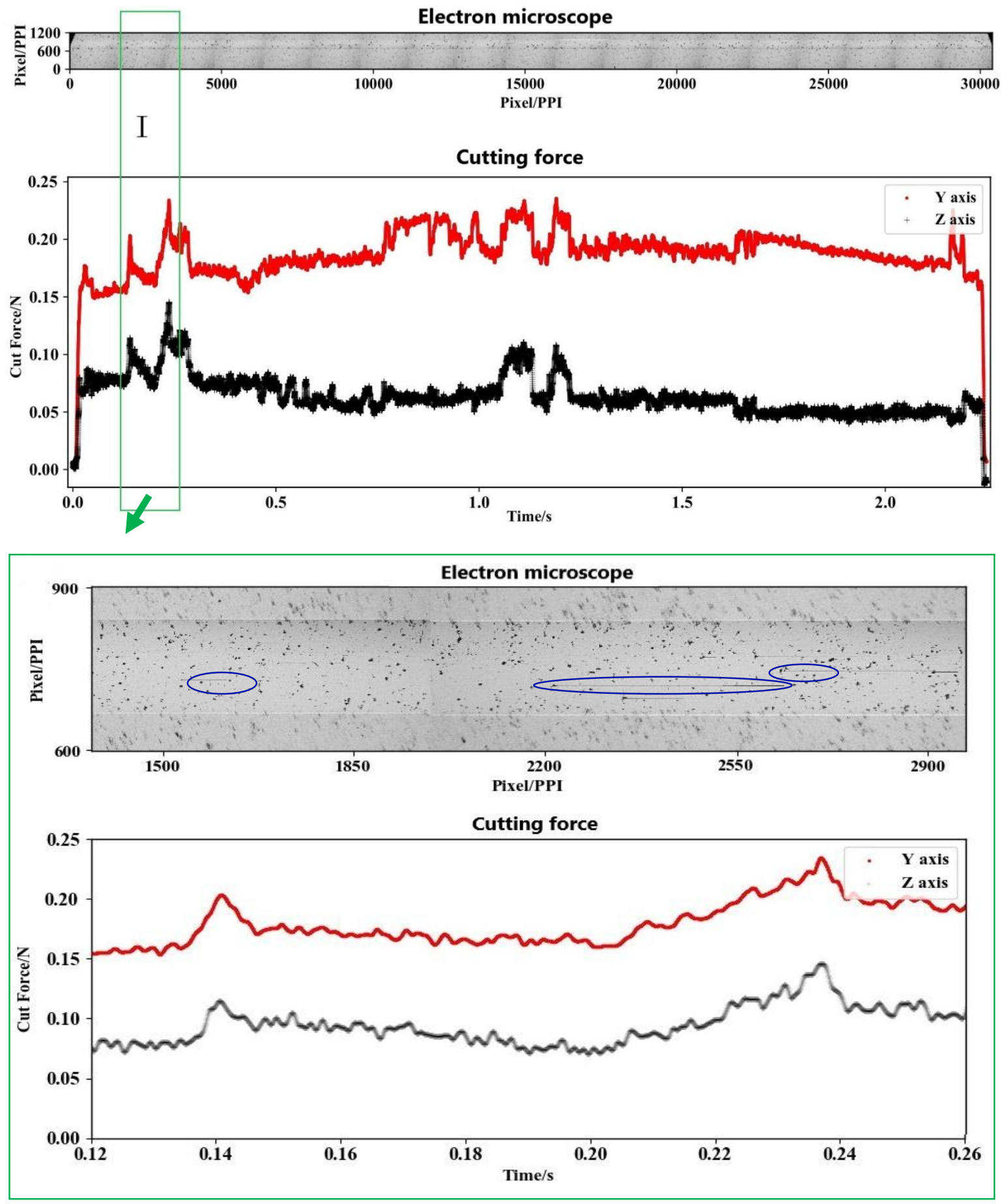

Figure 6. Force measurement in diamond cutting of Al6061. 
Therefore, during the diamond cutting of Al6061, heat is generated differently than during the cutting of non-age-hardenable alloys. This study investigated the relationship between precipitation generation and the friction coefficient of Al6061, by studying the effect of heat treatment on precipitation number and the friction coefficient of Al6061.

\section{Heat Treatment Experiment}

To study the properties of the generated precipitates (the white and black particles in Figures 4 and 5) on chips and the machined surface, three groups of heat treatment experiments were conducted: (1) solid solution treatments (samples were heated from room temperature to $520{ }^{\circ} \mathrm{C}$ at a speed of $10{ }^{\circ} \mathrm{C} / \mathrm{min}$ and held for $\left.1 \mathrm{~h}\right)$; (2) heat treatments using different temperatures $\left(100{ }^{\circ} \mathrm{C} ; 200{ }^{\circ} \mathrm{C} ; 300{ }^{\circ} \mathrm{C}\right.$; $\left.400^{\circ} \mathrm{C} ; 500^{\circ} \mathrm{C}\right)$ and ageing times $(2 \mathrm{~h} ; 4 \mathrm{~h} ; 8 \mathrm{~h} ; 12 \mathrm{~h})$; and (3) quenching in water at room temperature. After heat treatment, samples were examined using SEM, as shown in Figure 7 and Table 1.
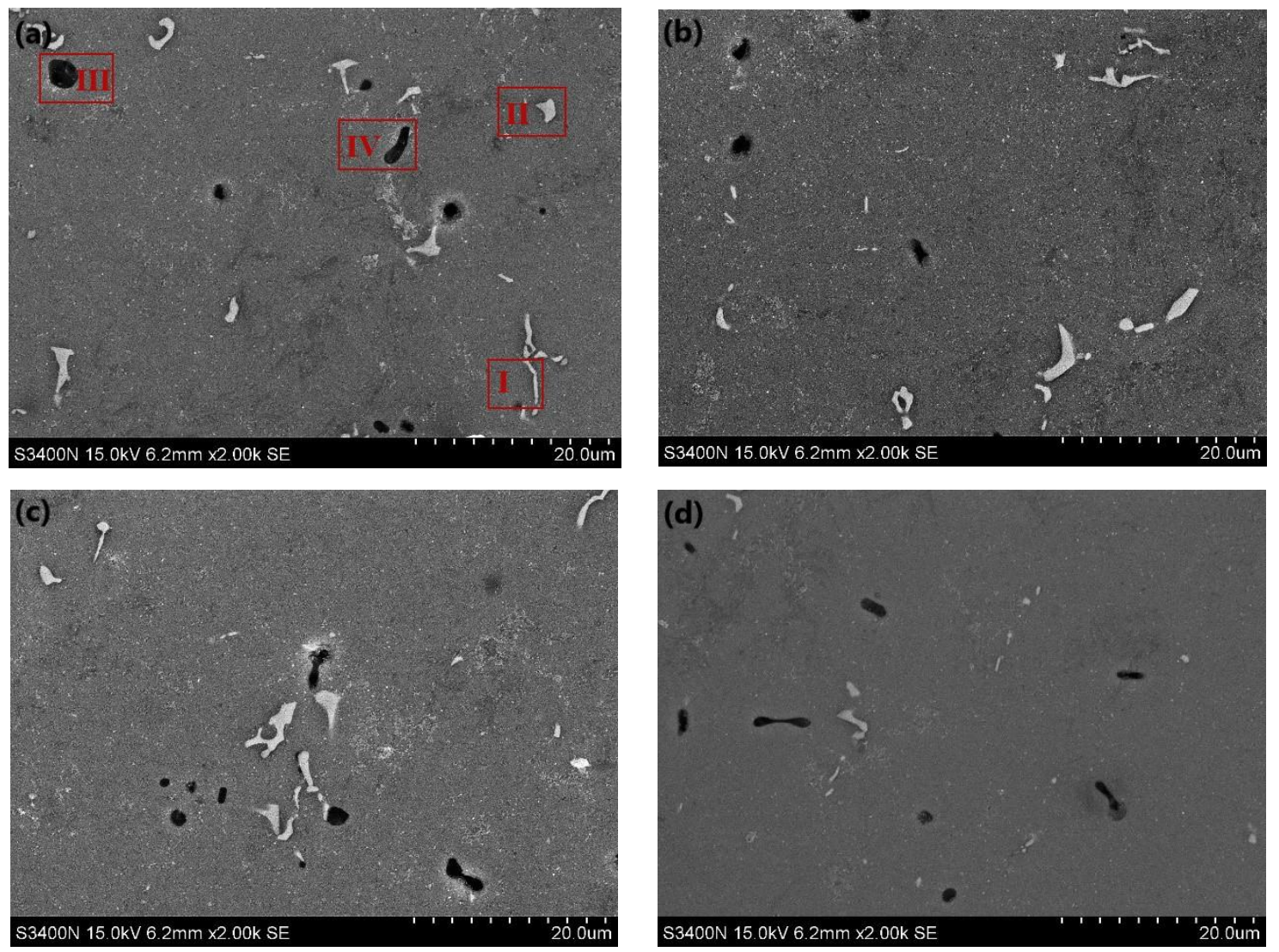

Figure 7. SEM image of Al6061 samples heated at $200{ }^{\circ} \mathrm{C}$ and held for different times: (a) $2 \mathrm{~h}$, (b) $4 \mathrm{~h}$, (c) $8 \mathrm{~h},(\mathrm{~d}) 12 \mathrm{~h}$

Table 1. EDX (energy-dispersive X-ray) results of the Al6061 sample in Figure 5a (Atomic \%).

\begin{tabular}{cccccccccc}
\hline Area No & $\mathbf{A l}$ & $\mathbf{M g}$ & $\mathbf{S i}$ & $\mathbf{F e}$ & $\mathbf{T i}$ & $\mathbf{C r}$ & $\mathbf{M n}$ & $\mathbf{N i}$ & $\mathbf{C u}$ \\
\hline I & 80.936 & 1.311 & $\mathbf{6 . 9 5 7}$ & $\mathbf{9 . 0 1 2}$ & 0.061 & 0.042 & 0.861 & 0.057 & 0.763 \\
II & 85.385 & 1.178 & $\mathbf{5 . 1 2 5}$ & $\mathbf{6 . 9 8}$ & 0.007 & 0.049 & 0.73 & 0.117 & 0.429 \\
III & 66.01 & $\mathbf{1 2 . 3 7 1}$ & $\mathbf{2 1 . 1 2 8}$ & 0.083 & 0.071 & 0.048 & 0.068 & 0.031 & 0.19 \\
IV & 67.545 & $\mathbf{1 1 . 9 1 1}$ & $\mathbf{2 0 . 0 0 8}$ & 0.063 & 0.056 & 0.06 & 0.073 & 0.053 & 0.231 \\
Base surface & 97.168 & 1.312 & 0.701 & 0.47 & 0.042 & 0.059 & 0.059 & 0.068 & 0.121 \\
\hline
\end{tabular}

As shown in Figure 7, the white precipitates had needle and block shapes, while most of the black precipitates were block-shaped. When compared with the EDX results in Table 1, the white needle-like particles (Area I in Figure 7a) and block-like particles (Area II in Figure 7a) were $\beta$-AlFeSi and $\alpha$-AlFeSi, 
respectively, while the black particles (Areas III and IV in Figure 7a) were $\mathrm{Mg}_{2} \mathrm{Si}$. As shown in Figures 4 and 5, the black particles were left on the chip, while the white ones were left on the generated surface, especially those white particles which induced scratch marks on the machined surface during the diamond cutting process. Therefore, this study focused on the generation of white particles ( $\beta-$, $\alpha$-AlFeSi) on diamond-machined Al6061, and their effect on the tool-workpiece fiction coefficient. Figure 8 shows the number of AlFeSi particles generated using different heating temperatures and heating times. Note that the particle amounts in Figure 8 refer to averages over five evaluations using the same heat treatment. As shown in Figure 8, with different heating temperatures and heating times, the number of AlFeSi particles generated varied $(\mathrm{P}<0.01)$.

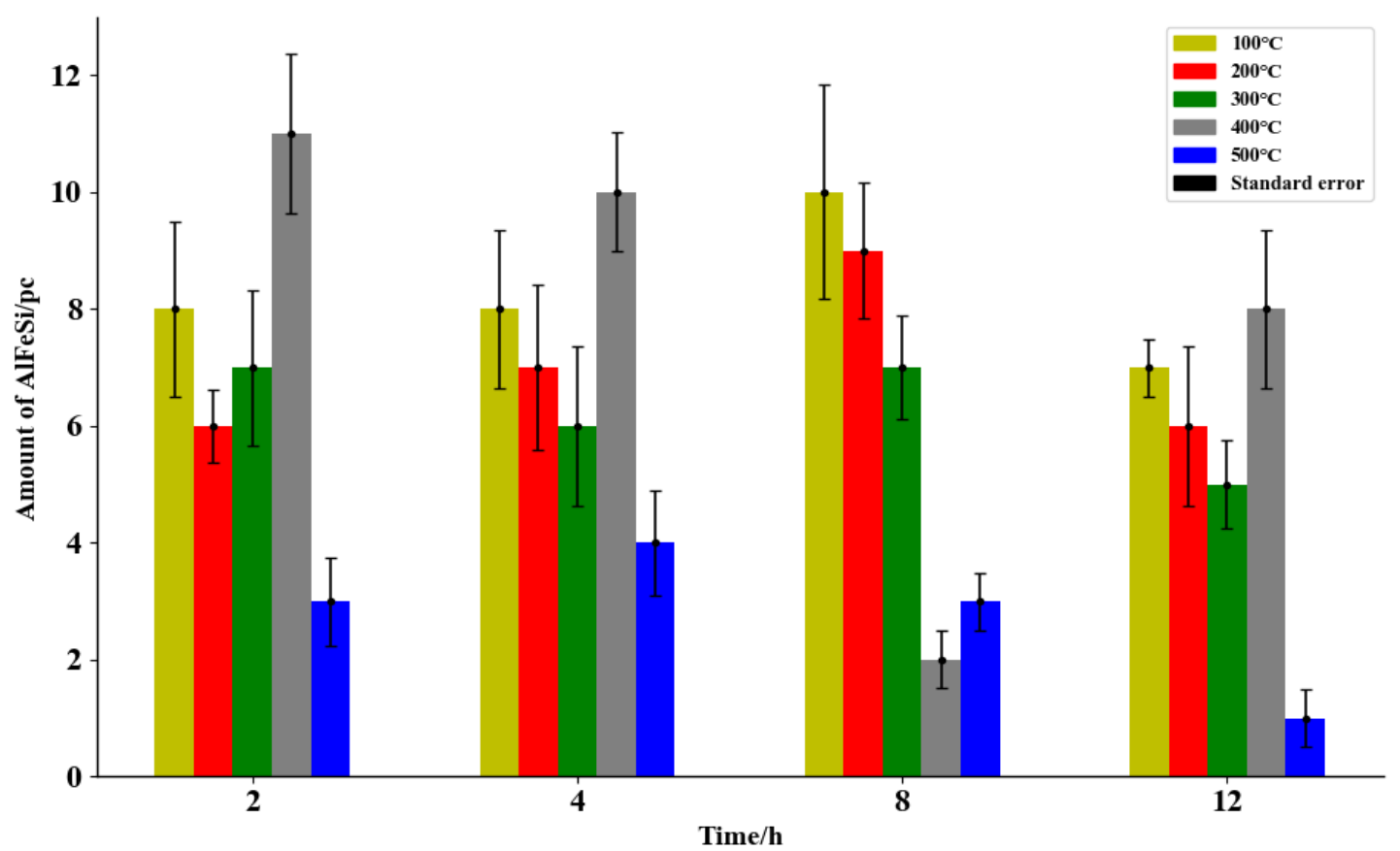

Figure 8. Effects of heating time and heating temperature on the amount of AlFeSi.

\section{Friction Test Experiment}

To study the effect of precipitate generation on tool-workpiece friction during diamond cutting of Al6061, all the heat-treated samples were polished to conduct a friction test on a tribology system (Bruker UMT Tribolab). This is shown in Figure 9. During the friction test, the sample on the table moved along the $X$-axis with a speed of $5 \mathrm{~mm} / \mathrm{s}$. The length of the $X$-axis was $10 \mathrm{~mm}$. The friction tool was a steel ball with a diameter of $6.5 \mathrm{~mm}$. The loads in the Z-axis direction and the friction time were $2 \mathrm{~N}$ and $10 \mathrm{~min}$, respectively. Figure 10 presents the surface quality of the polished surface. After the friction test, the samples were examined using SEM, as shown in Figure 11. It was found that there were scratch marks, cracks and pits on the friction surface similar to those on the diamond-machined surface (Figure 5).

Figure 12a presents the initial data from the friction test and Figure $12 \mathrm{~b}$ presents the data obtained between 2.5 and $20 \mathrm{~s}$. Using the coordinate system in Figure 9, $F_{x}$ (red in Figure 12) refers to the friction force in $\mathrm{X}$-axis direction, and $\mathrm{F}_{\mathrm{Z}}$ (green in Figure 12) is the load force in the Z-axis direction. As Figure 12a shows, as the friction time gets longer, the friction depth increases. This implies a larger contact area between the materials and the tool, inducing larger variation ranges for the $\mathrm{X}$-axis friction force $\left(F_{X}\right)$ and the $Z$-axis load force $\left(F_{Z}\right)$. Moreover, in Figure $12 b$, it can be seen that both the friction coefficient and the two forces $\left(F_{x}\right.$ and $\left.F_{z}\right)$ change periodically with the $X$-axis friction velocity (blue Figure 12). Where there are peaks and valleys in the $\mathrm{X}$-axis friction velocity profile, Z-axis loading force and $\mathrm{X}$-axis friction fluctuate especially greatly. 


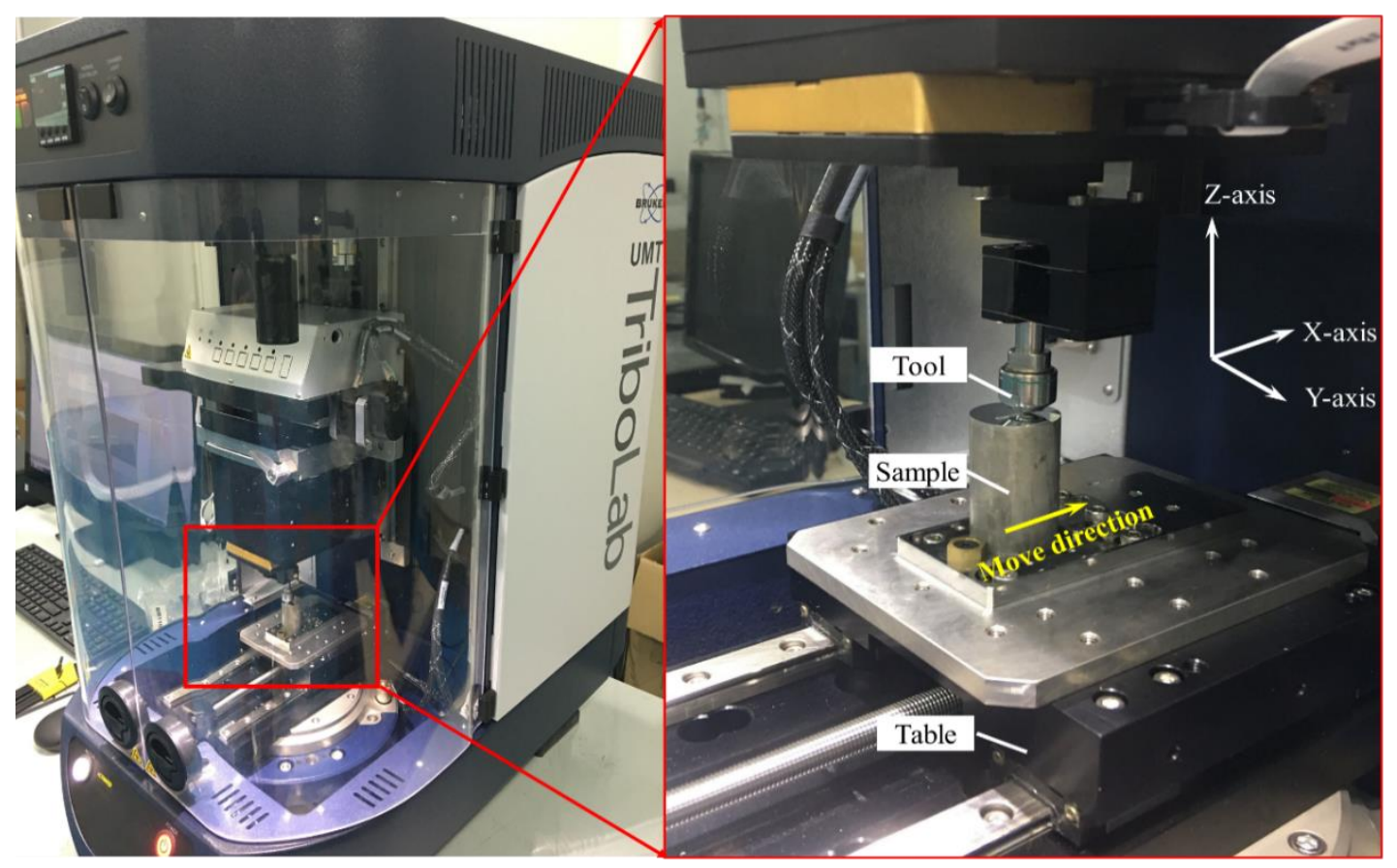

Figure 9. Friction test on Bruker UMT Tribolab.

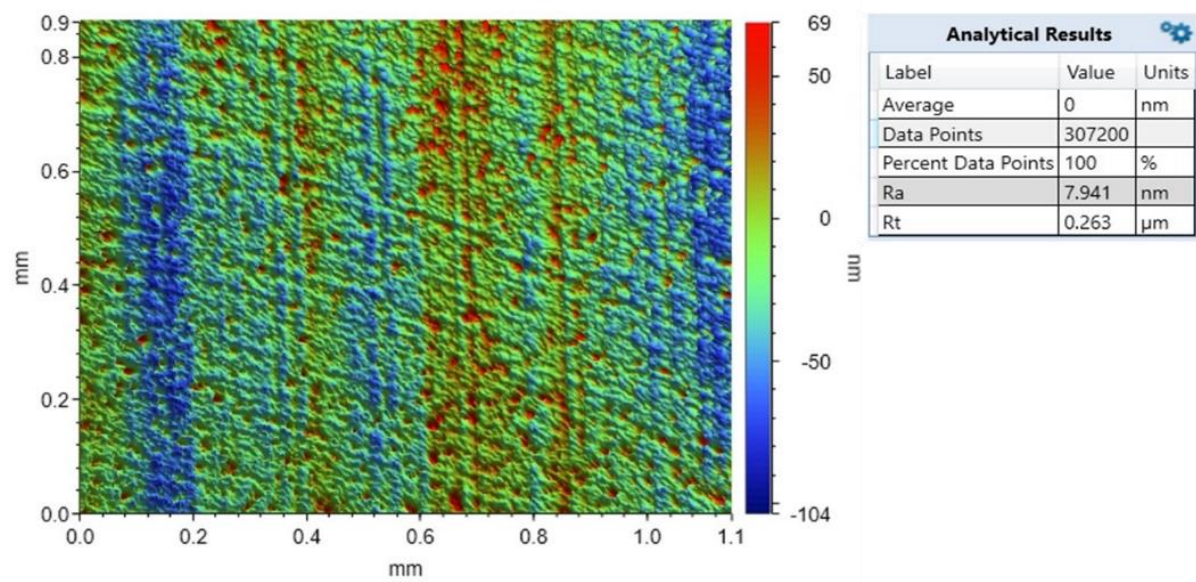

Figure 10. Surface quality evaluation result for the polished Al6061 samples.

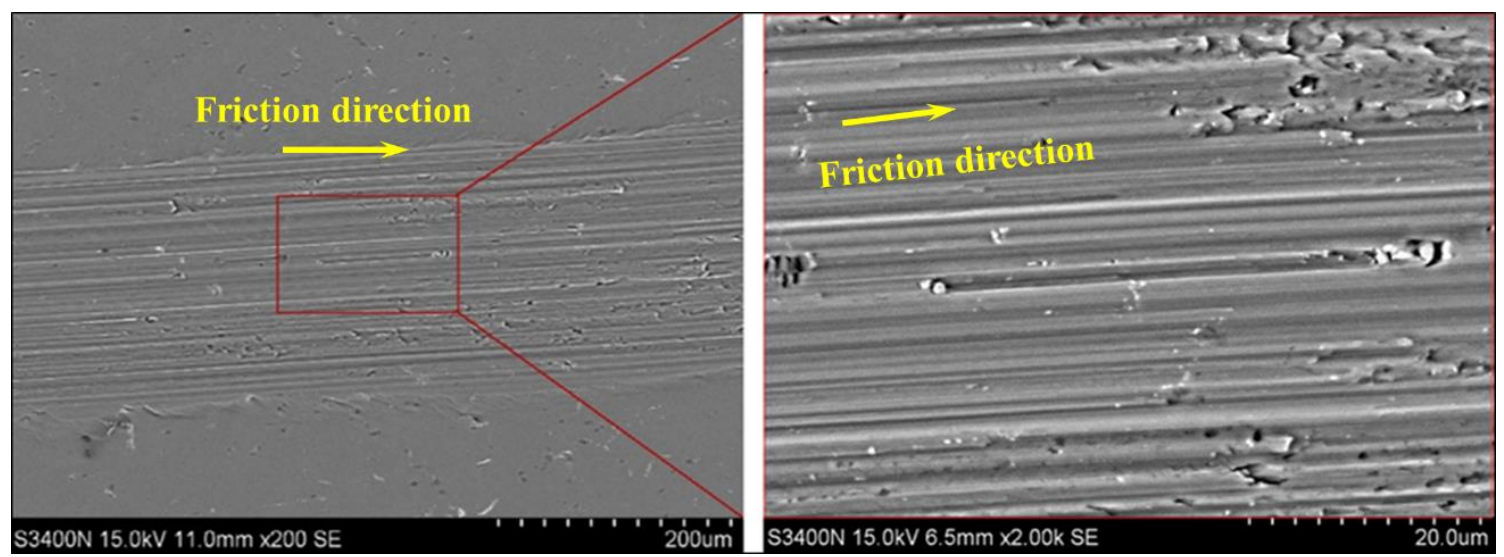

Figure 11. SEM images of the Al6061 sample after the friction test. 

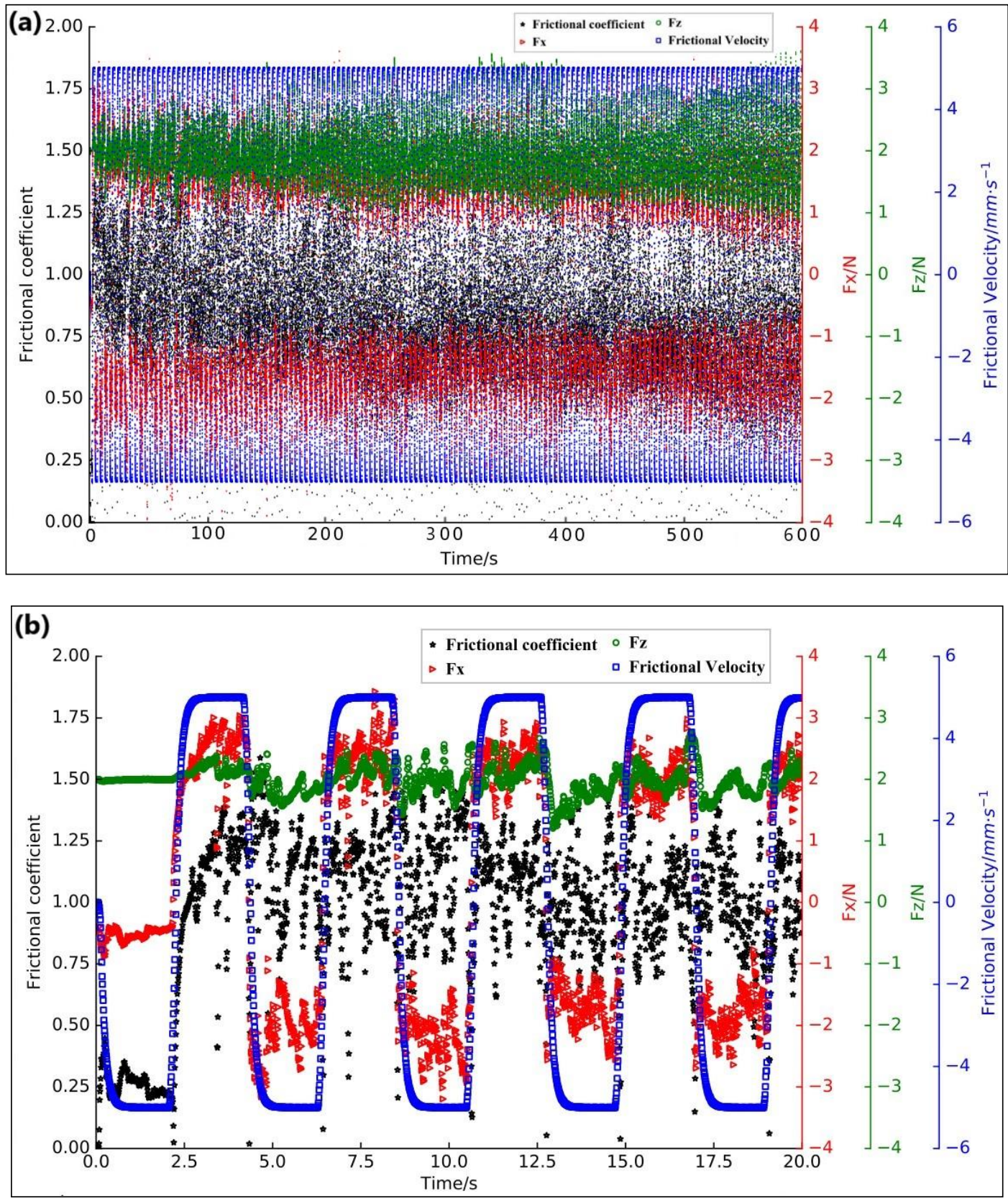

Figure 12. Friction test results of Al6061 sample: (a) the original data, (b) the data with $2.5 \mathrm{~s} \sim 20 \mathrm{~s}$.

To more precisely characterize the friction coefficient of Al6061, the original data were therefore processed with two steps: (1) data which fluctuated greatly-that is, data near the peaks and valleys of the friction velocity profile-were filtered out; (2) low-pass mean filtering was applied to the Z-axis loading force and X-axis friction, as shown in Figure 13. After that, all of the Al6061 samples (with different heating temperatures and different heating times) were examined for each of the 6 tests and the average value of the friction coefficients was evaluated (Figure 14). 


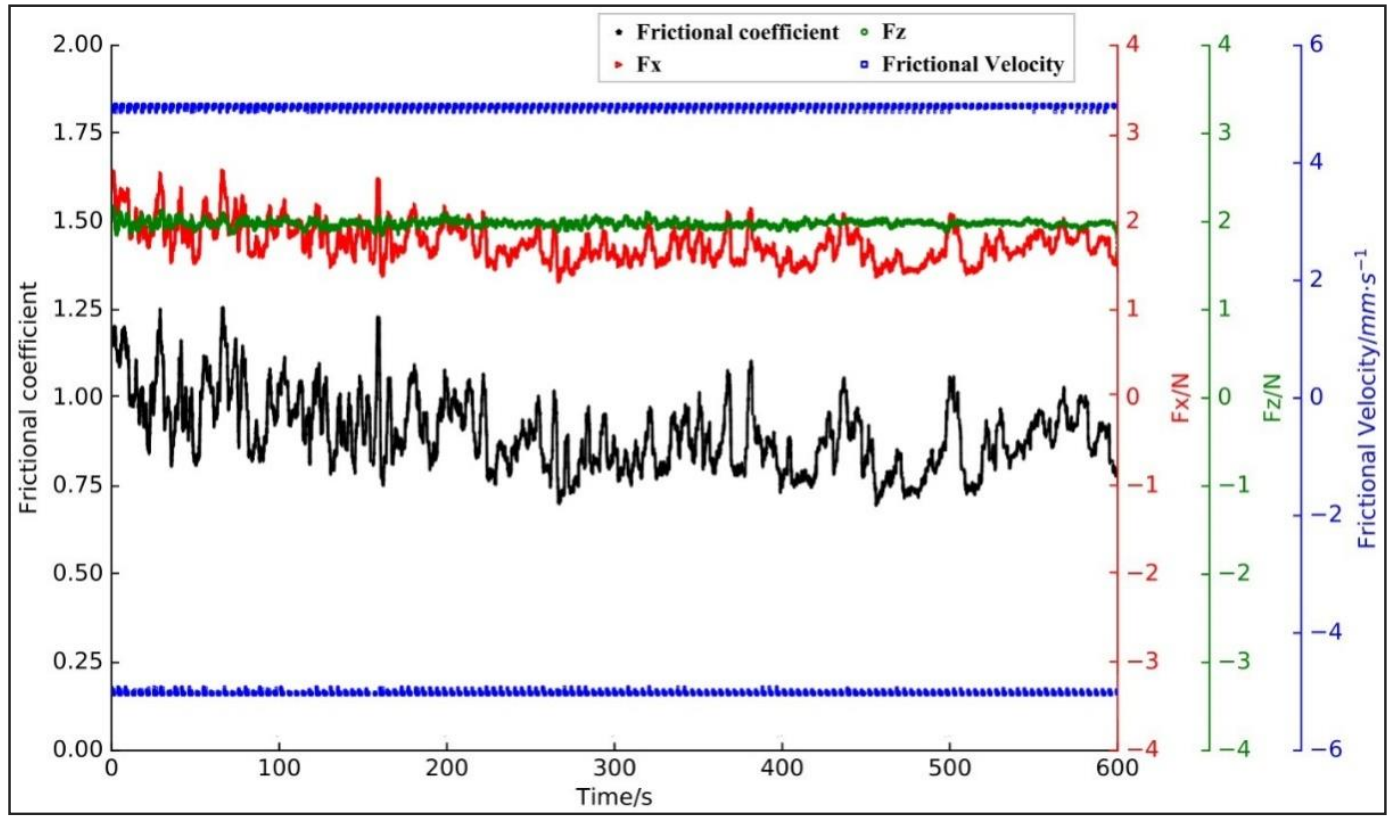

Figure 13. The friction test results after data processing.

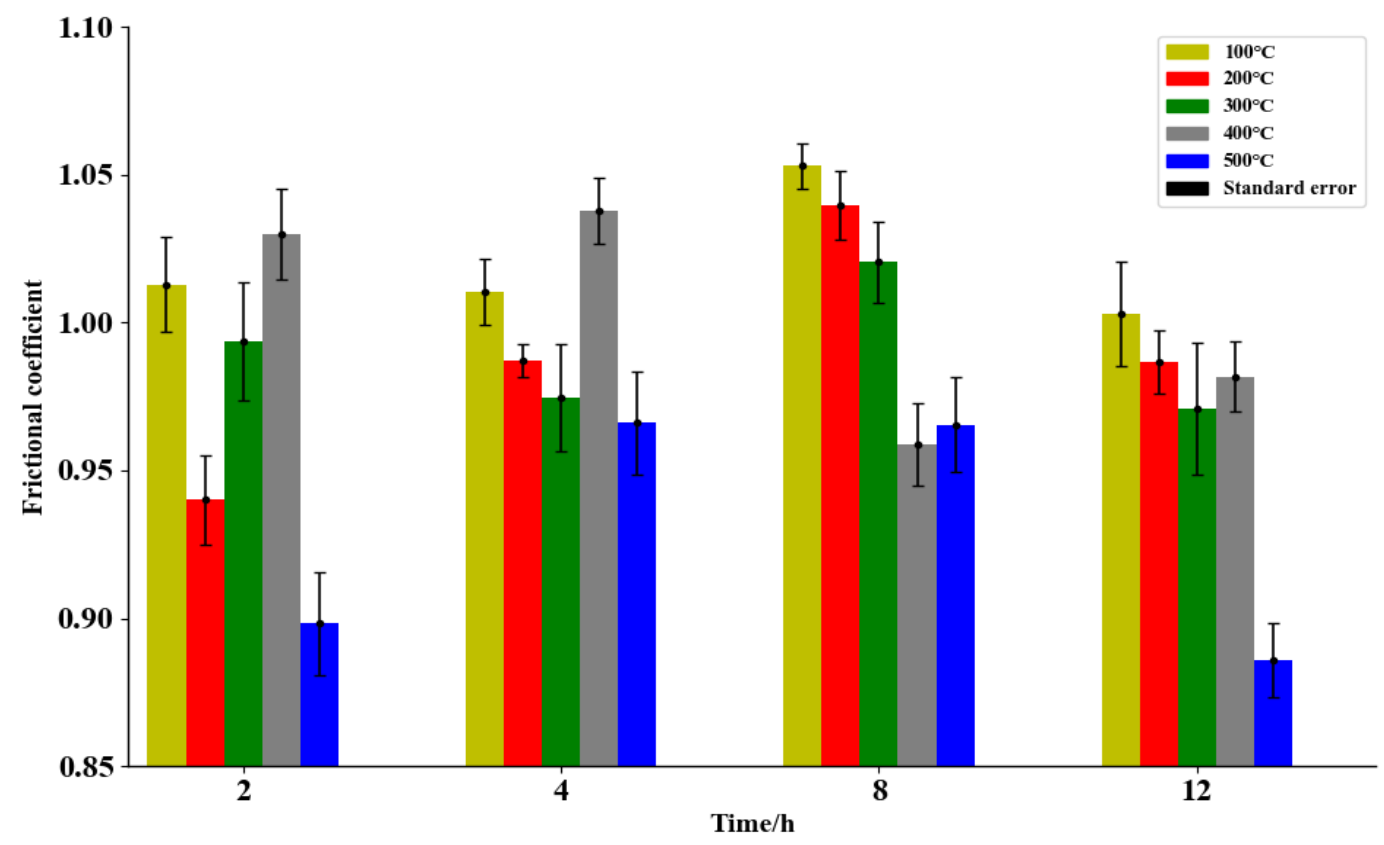

Figure 14. Effects of heating temperature and heating time on the friction coefficient of Al6061.

As Figure 14 shows, under different heating times and heating temperatures, the friction coefficient of Al6061 varied $(\mathrm{P}<0.05)$. When aging time was $2 \mathrm{~h}, 4 \mathrm{~h}$ or $12 \mathrm{~h}$, the friction coefficient first rose then fell with increasing temperature. However, when aging time was $8 \mathrm{~h}$, a different phenomenon was found. Compared to the influence of heat conditions on the number of AlFeSi particles, as displayed in Figure 6, the variation trend of the friction coefficient was similar. Referring to Figures 8 and 14, the relationship between the amount of AlFeSi and the friction coefficient can be determined. As shown in Figure 15, the increased amount of AlFeSi induced a larger friction coefficient (correlation coefficient: $\mathrm{R}^{2}=0.7659$ ). Moreover, the measured friction coefficients ranged from 0.85 to 1.06 , which is higher than the static friction coefficient between steel and aluminum alloy (0.2-0.8) [16]. One reason for this is that the Al6061 samples were heat-treated and the particles generated on the surface decreased the surface quality, increasing the friction coefficient. Therefore, the generation of AlFeSi particles of 
Al6061 is an important factor influencing the tool-workpiece friction coefficient during the machining of Al-Mg-Si alloys. This also affects the freshly generated surface, and therefore the achieved surface quality in ultra-precision machining.

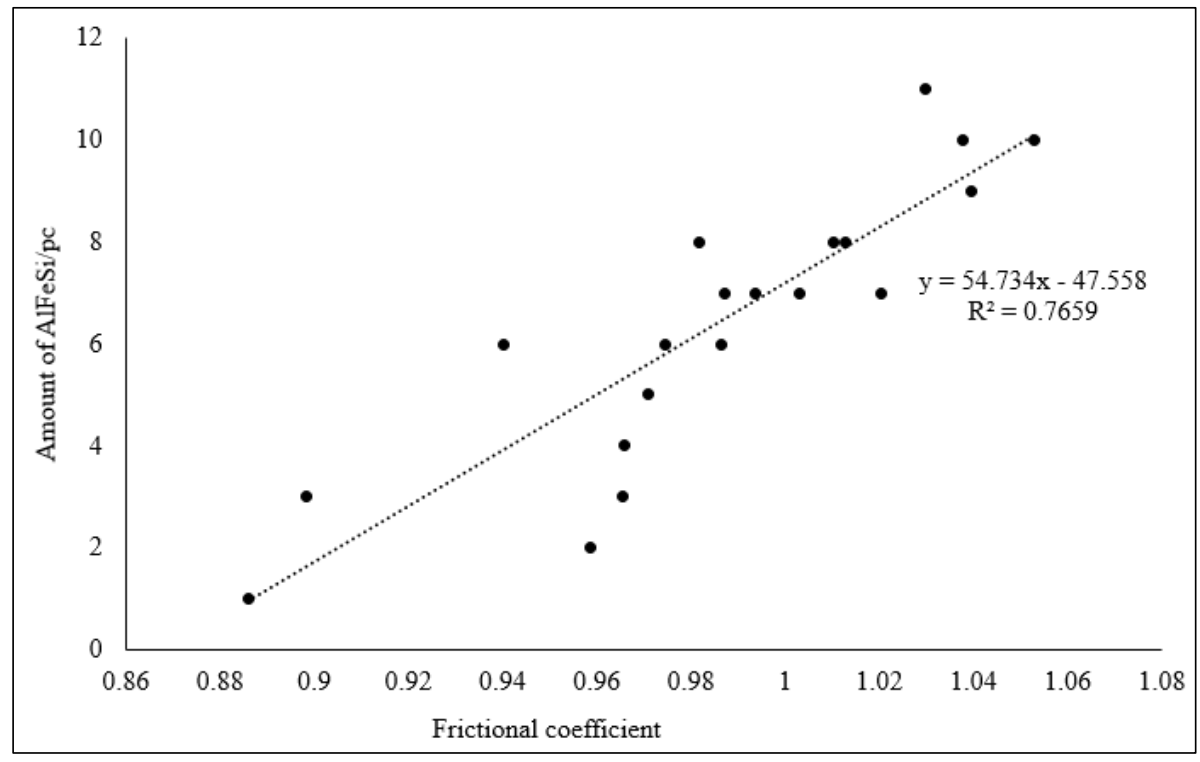

Figure 15. Relationship between the AlFeSi particles and the friction coefficient of Al6061.

\section{Conclusions}

We conducted groups of experiments to study the effect of precipitation generation in Al6061 on the friction coefficient during ultra-precision machining. The major findings can be summarized as follows:

- $\quad$ The cutting-induced heat in diamond cutting of Al6061 generated different types of precipitates on the chips and the machined surface.

- $\quad$ The AlFeSi particles generated during diamond cutting of Al6061 induced scratch marks, cracks and pits on the machined surface.

- This affects surface quality, changing the cutting forces and the contact conditions at the tool-chip and tool-workpiece interfaces.

- The number of AlFeSi particles in the Al6061 samples varied with different heating effects.

- The friction coefficients of the Al6061 samples were characterized in this study. The trend of the friction coefficients was similar to that of the AlFeSi particle number.

With the successful establishment of a relationship between the precipitate number and friction coefficient of Al6061, the effect of heating treatment on friction coefficient of Al6061 has been investigated. This study provides an important means for better understanding the mechanisms of surface generation and chip formation in ultra-precision machining, and contributes to the further development of a more precise numerical cutting model for ultra-precision machining, especially for precipitation-hardened alloys.

Author Contributions: H.W.: To conduct experiments, collect data and analyze data; T.Z.: Literature search, figures, manuscript format; S.W. and S.T.: Experiment design, manuscript writing and theoretical analyses; S.T.: Idea provide. All authors have read and agreed to the published version of the manuscript.

Funding: The authors would like to express their sincere thanks for the support of National Natural Science Foundation of China (no. 51975128).

Conflicts of Interest: The authors declare no conflict of interest. 


\section{References}

1. Miller, W.S.; Zhuang, L.; Bottema, J.; Wittebrood, A.J.; De Smet, P.; Haszler, A.; Vieregge, A. Recent development in aluminium alloys for the automotive industry. Mater. Sci. Eng. A 2000, 280, 37-49. [CrossRef]

2. HIRSCH, J. Recent development in aluminium for automotive applications. T. Nonferr. Metal. Soc. 2014, 24, 1995-2002. [CrossRef]

3. Zhan, H.; Mol, J.M.C.; Hannour, F.; Zhuang, L.; Terryn, H.; de Wit, J.H.W. The influence of copper content on intergranular corrosion of model AlMgSi $(\mathrm{Cu})$ alloys. Mater. Corros. 2008, 59, 670-675. [CrossRef]

4. Sekhar, A.P.; Mandal, A.B.; Das, D. Mechanical properties and corrosion behavior of artificially aged Al-Mg-Si alloy. J. Mater. Res. Technol. 2020, 9, 1005-1024. [CrossRef]

5. Kairy, S.K.; Rometsch, P.A.; Diao, K.; Nie, J.F.; Davies, C.H.J.; Birbilis, N. Exploring the electrochemistry of 6xxx series aluminium alloys as a function of $\mathrm{Si}$ to $\mathrm{Mg}$ ratio, $\mathrm{Cu}$ content, ageing conditions and microstructure. Electrochim. Acta. 2016, 190, 92-103. [CrossRef]

6. Wang, S.; To, S.; Chen, X.; Chen, X. An investigation on surface finishing in ultra-precision raster milling of aluminum alloy 6061. Proc. Inst. Mech. Eng. Part B 2014, 229, 1289-1301. [CrossRef]

7. Kwon, K.B.; Cho, D.W.; Lee, S.J.; Chu, C.N. A Fluid Dynamic Analysis Model of the Ultra-Precision Cutting Mechanism. CIRP Ann. 1999, 48, 43-46. [CrossRef]

8. Moriwaki, T.; Horiuchi, A.; Okuda, K. Effect of Cutting Heat on Machining Accuracy in Ultra-Precision Diamond Turning. CIRP Ann. 1990, 39, 81-84. [CrossRef]

9. Kim, K.W.; Lee, W.Y.; Sin, H. A finite element analysis for the characteristics of temperature and stress in micro-machining considering the size effect. Int. J. Mach. Tools Manuf. 1999, 39, 1507-1524. [CrossRef]

10. Wang, S.J.; Chen, X.; To, S.; Ouyang, X.B.; Liu, Q.; Liu, J.W.; Lee, W.B. Effect of cutting parameters on heat generation in ultra-precision milling of aluminum alloy 6061. Int. J. Adv. Manuf. Technol. 2015, 80, 1265-1275. [CrossRef]

11. Abukhshim, N.A.; Mativenga, P.T.; Sheikh, M.A. Heat generation and temperature prediction in metal cutting: A review and implications for high speed machining. Int. J. Mach. Tools Manuf. 2006, 46, 782-800. [CrossRef]

12. Melkote, S.N.; Grzesik, W.; Outeiro, J.; Rech, J.; Schulze, V.; Attia, H.; Arrazola, P.; M Saoubi, R.; Saldana, C. Advances in material and friction data for modelling of metal machining. CIRP Ann. 2017, 66, 731-754. [CrossRef]

13. Rech, J.; Giovenco, A.; Courbon, C.; Cabanettes, F. Toward a new tribological approach to predict cutting tool wear. CIRP Ann. 2018, 67, 65-68. [CrossRef]

14. Mondelin, A.; Valiorgue, F.; Rech, J.; Coret, M.; Feulvarch, E. Hybrid model for the prediction of residual stresses induced by 15-5PH steel turning. Int. J. Mech. Sci. 2012, 58, 69-85. [CrossRef]

15. Özel, T. The influence of friction models on finite element simulations of machining. Int. J. Mach. Tools Manuf. 2006, 46, 518-530. [CrossRef]

16. Benabdallah, H.S. Static friction coefficient of some plastics against steel and aluminum under different contact conditions. Tribol. Int. 2007, 40, 64-73. [CrossRef]

17. Fuh, K.; Wu, C. A residual-stress model for the milling of aluminum alloy (2014-T6). J. Mater. Process. Technol. 1995, 51, 87-105. [CrossRef]

18. Shaw, M.C. Metal Cutting Principles; Oxford University Press: Oxford, UK, 2005; Volume 2.

19. Trent, E.M.; Wright, P.K. Metal Cutting; Butterworth-Heinemann: Oxford, UK, 2000.

20. Atlati, S.; Haddag, B.; Nouari, M.; Zenasni, M. Thermomechanical modelling of the tool-workmaterial interface in machining and its implementation using the ABAQUS VUINTER subroutine. Int. J. Mech. Sci. 2014, 87, 102-117. [CrossRef]

21. Pan, L.S.; Kania, D.R. Diamond: Electronic Properties and Applications; Springer Science \& Business Media: Berlin, Germany, 2013.

22. Olson, J.R.; Pohl, R.O.; Vandersande, J.W.; Zoltan, A.; Anthony, T.R.; Banholzer, W.F. Thermal conductivity of diamond between 170 and $1200 \mathrm{~K}$ and the isotope effect. Phys. Rev. B 1993, 47, 14850-14856. [CrossRef] [PubMed]

(C) 2020 by the authors. Licensee MDPI, Basel, Switzerland. This article is an open access article distributed under the terms and conditions of the Creative Commons Attribution (CC BY) license (http://creativecommons.org/licenses/by/4.0/). 